\title{
A Skin-Conformal, Stretchable, and Breathable Fiducial Marker Patch for Surgical Navigation Systems
}

\author{
Sangkyu Lee ${ }^{1,+} \oplus$, Duhwan Seong ${ }^{1,+}$, Jiyong Yoon ${ }^{1}$, Sungjun Lee ${ }^{2}$, Hyoung Won Baac ${ }^{1}{ }^{1}$, \\ Deukhee Lee ${ }^{3, * \mathbb{D}}$ and Donghee Son ${ }^{1, *(\mathbb{D})}$ \\ 1 Department of Electrical and Computer Engineering, Sungkyunkwan University, Suwon 16419, Korea; \\ lee39@g.skku.edu (S.L.); dodoworld1993@gmail.com (D.S.); jiyong428@g.skku.edu (J.Y.); \\ hwbaac@skku.edu (H.W.B.) \\ 2 Center for Bionics of Biomedical Research Institute, Korea Institute of Science and Technology, \\ Seoul 02792, Korea; leesj9883@kist.re.kr \\ 3 Center for Medical Robotics, Korea Institute of Science and Technology, Seoul 02792, Korea \\ * Correspondence: dkylee@kist.re.kr (D.L.); daniel3600@g.skku.edu (D.S.); Tel.: +82-31-290-7696 (D.S.) \\ + These authors equally contributed to this work.
}

Received: 6 January 2020; Accepted: 11 February 2020; Published: 13 February 2020

\begin{abstract}
Augmented reality (AR) surgical navigation systems have attracted considerable attention as they assist medical professionals in visualizing the location of ailments within the human body that are not readily seen with the naked eye. Taking medical imaging with a parallel C-shaped arm (C-arm) as an example, surgical sites are typically targeted using an optical tracking device and a fiducial marker in real-time. These markers then guide operators who are using a multifunctional endoscope apparatus by signaling the direction or distance needed to reach the affected parts of the body. In this way, fiducial markers are used to accurately protect the vessels and nerves exposed during the surgical process. Although these systems have already shown potential for precision implantation, delamination of the fiducial marker, which is a critical component of the system, from human skin remains a challenge due to a mechanical mismatch between the marker and skin, causing registration problems that lead to poor position alignments and surgical degradation. To overcome this challenge, the mechanical modulus and stiffness of the marker patch should be lowered to approximately $150 \mathrm{kPa}$, which is comparable to that of the epidermis, while improving functionality. Herein, we present a skin-conformal, stretchable yet breathable fiducial marker for the application in AR-based surgical navigation systems. By adopting pore patterns, we were able to create a fiducial marker with a skin-like low modulus and breathability. When attached to the skin, the fiducial marker was easily identified using optical recognition equipment and showed skin-conformal adhesion when stretched and shrunk repeatedly. As such, we believe the marker would be a good fiducial marker candidate for patients under surgical navigation systems.
\end{abstract}

Keywords: fiducial marker; augmented reality; surgical navigation systems; skin-conformal; adhesive patch

\section{Introduction}

With the fast-paced development of medical diagnostic technology in recent times, surgical techniques based on augmented reality (AR) have needed to be introduced for medical procedures. Particularly, surgical navigation systems with optical tracking devices and cameras have the ability to observe affected parts of the human body which can normally not be seen with the naked eye [1-5]. AR-based surgical navigation systems typically use markers and optical tracking devices, such as near 
infrared (IR) cameras, to visualize affected parts of the body as an image displayed on a monitor to enable more precise surgery (Figure 1a) [6,7]. At present, the fiducial marker uses an optical tracking device to register the position between the patient and the image so as to accurately determine surgical positioning. In this case, metal-based markers are often used for this purpose [8-10]. However, these conventional markers are disadvantageous in some cases as they are too rigid, and their temporary adhesion is not good enough during a surgery. These temporary adhesion properties cause markers to slip, particularly if a procedure is postponed with the marker left on the body for extended periods or when the patient suddenly moves during the operation. Should this scenario occur and the fiducial marker misaligns, the exact positioning on the body may be missed entirely, reducing the precision of the surgery, which can ultimately lead to a medical accident. Of the conventional fiducial markers available on the market, no marker possesses a skin-like modulus (about $\sim 150 \mathrm{kPa}$ ) nor stretchability $(\sim 30 \%)$ to permit adhering to any human movements recognizable for diagnostic medical techniques. Several infrared (IR) light-emitting diode (LED)-based fiducial markers have been reported to date. However, almost all are for non-medical purposes or based on rigid substrates. They are neither stretchable nor skin-conformal [11-13]. Due to these challenges, we undertook a proof-of-concept study and designed a stretchable electronics system for a new conceptual fiducial marker. Stretchable electronics system means a system consisted of integrated intrinsically stretchable material-based devices, such as LEDs, transistors and sensors, and stretchable interconnect materials on a skin-like rubber substrate [14-36]. However, these devices based on stretchable electronics do suffer from an inherent weakness to external damage and its fabrication process is often difficult and expensive. In order to overcome these problems, researchers have recently been studying polymers with self-healing properties as a potential substrate instead of a rubber [37-50].

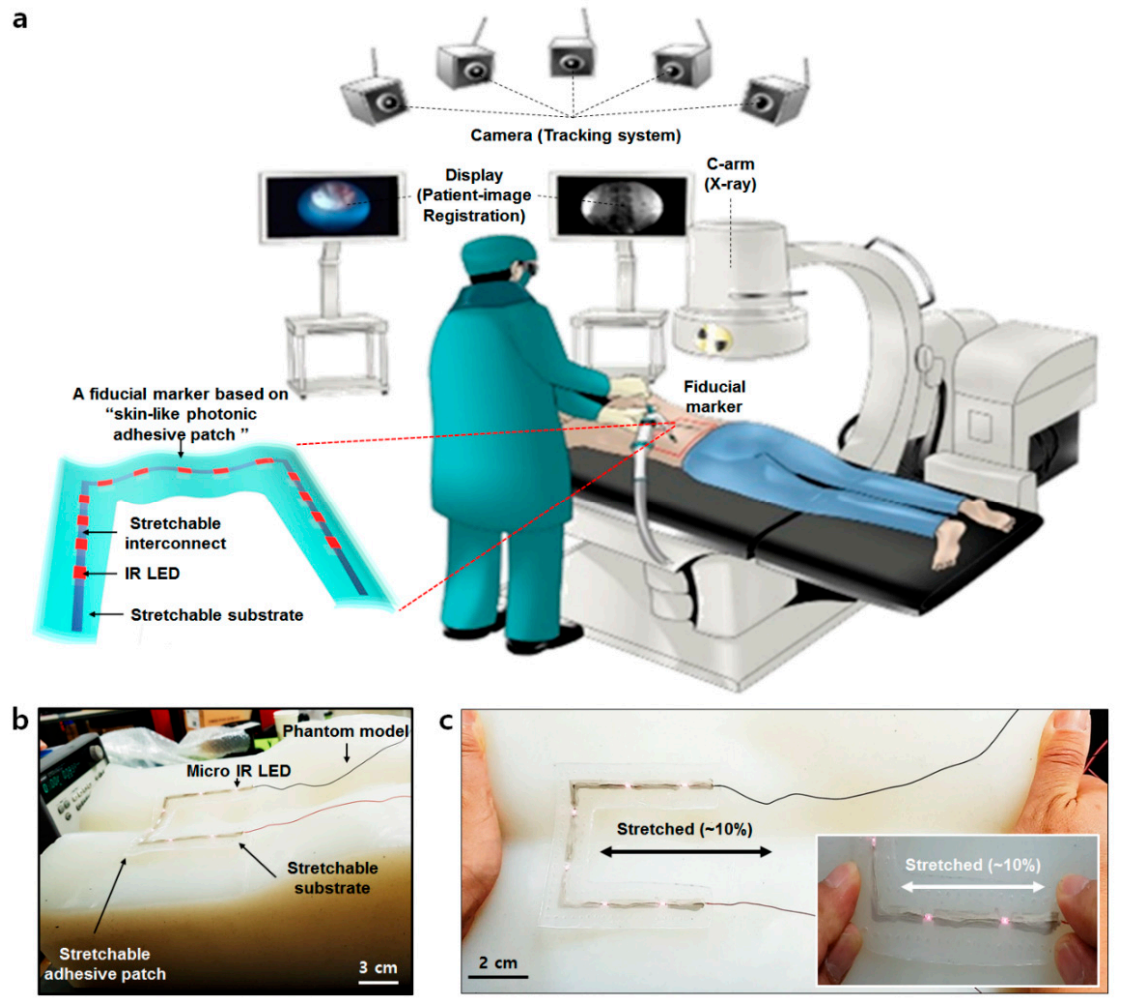

Figure 1. Schematic of a surgery navigation system and skin-conformal fiducial marker patch. (a) Schematic of an overall surgery navigation system and its components. (b) The components of the fiducial marker patch. (c) The stretchability of the fiducial marker patch.

In this paper, we introduce a skin-conformal, stretchable, and breathable fiducial marker with human "skin-like" mechanical properties $(\sim 150 \mathrm{kPa})$ and breathability by the adoption of pore patterns. 
This patch had the ability to maintain its light emission properties when attached to a silicone phantom model and stretched (Figure 1b,c). The patch was also clearly recognized through the near-IR camera and micro-CT machine. It also showed conformal adhesion to the skin when a patient moved. As such, we believe the patch may be a good fiducial marker candidate for patients under surgical navigation systems.

\section{Materials and Methods}

\subsection{Synthesis of Fiducial Marker}

Our fiducial marker was synthesized as outlined in Figure 2a. First, a commercial silicone rubber solution (Ecoflex 00-30, Smooth-on Inc., Easton, PA, USA), employed for its stretchable properties, was mixed and poured into a square petri-dish $(12 \mathrm{~cm} \times 11 \mathrm{~cm})$ and then dried and cured for approximately $3 \mathrm{~h}$. After peeling off the substrate, it was then moved into a $10 \mathrm{~cm} \times 10 \mathrm{~cm}$ plate, with the edges of the substrate cut to make a square shape. To screen-print the interconnect material, a shadow mask (stainless steel mask, iNEX JK Co., Ltd., Hwaseong, South Korea) was placed on the substrate. After this, a certain amount of conductive silver ink (PE873, Dupont) was collected in front of the exposed pattern area on the mask, screen-printed with a glass slide, and cured (an hour, $120^{\circ} \mathrm{C}$ ) to create an interconnect for the micro-IR LEDs (QBLP650-IR3, $850 \mathrm{~nm}$, QT Brightek, San Francisco, CA, USA) with soldered wire on their end. The micro-IR LEDs were then attached to the empty site between interconnects on the substrate, and two wires on their ends attached to both ends of the interconnect lines with a silicon adhesive (Silpoxy, Smooth-on Inc.) before being cured at 30 min to fix them. Next, conductive ink was also applied on the interconnect site and cured again. At this stage, the stretchability of the substrate and interconnect were shortly tested manually and quantitively. In manual, they were stretched by two hands. Moreover, a digital multimeter (Keithley 2450 sourcemeter, Tektronix, OR, USA) and motor-based one-axis stretcher (SMC-100, Jaeil optical system, Incheon, South Korea) were used for the cyclic stretching test.

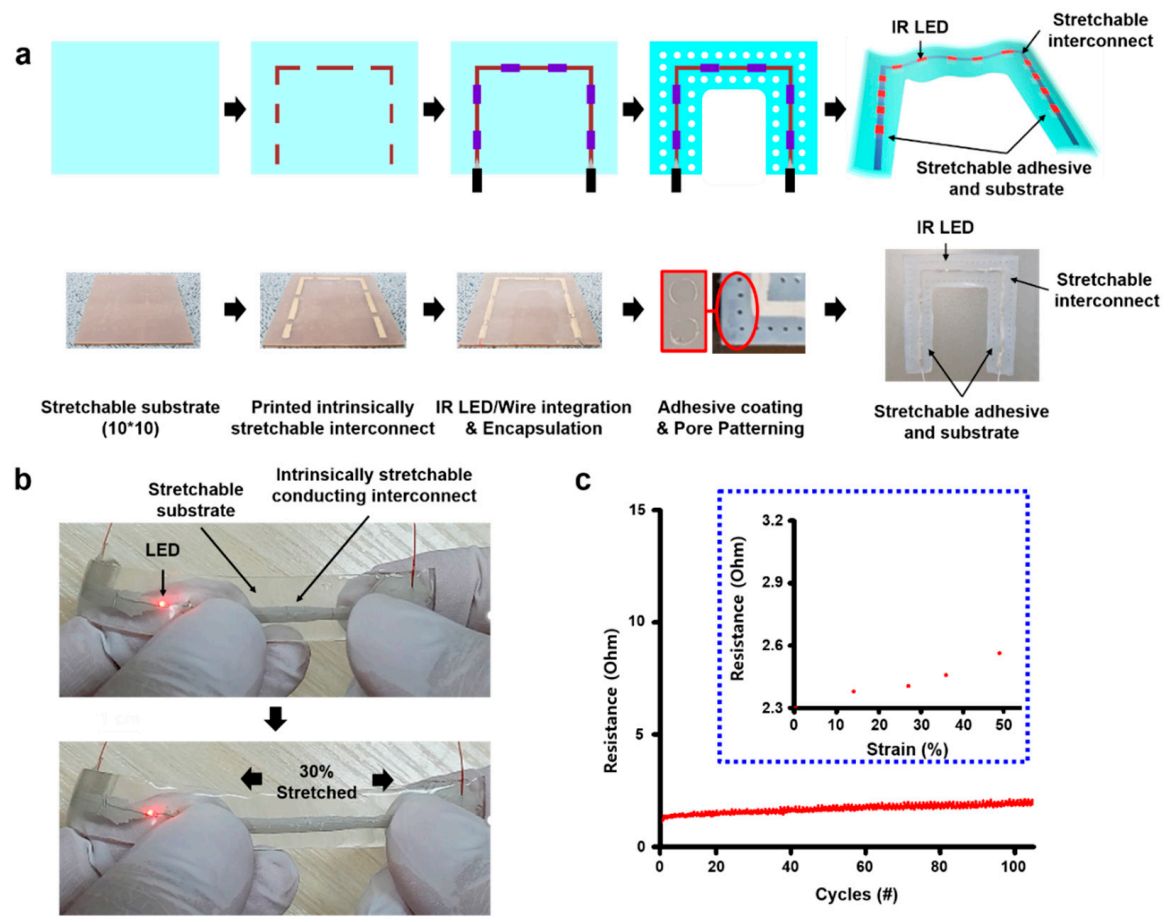

Figure 2. Marker patch fabrication process and the stretchability of interconnect material on the patch. (a) Patch fabrication process. (b) The stretchability of the patch interconnect part with micro-IR LEDs when it was stretched to $30 \%$ by two hands. (c) Electrical stability of the interconnect part by 100 cycle stretching test. Inset: the resistance change of the interconnect part by strain. 
Afterward, the substrate solution was then applied in a way to encapsulate all components of the patch again. Furthermore, the center part of the patch was cut into a square to form a U-shaped patch to be used as a fiducial marker. A suitable adhesive (Silbione RT gel 4717, Elkem Silicones, Oslo, Norway) was then applied to the back of the patch and cured to make an adhesive layer. Finally, pores were drilled using a commercial punch (3 mm-diameter Miltex biopsy punch, Schuco, Watford, United Kingdom) throughout the substrate within $5 \mathrm{~mm}$ intervals between the pores, except for parts around interconnects, to give the patch a skin-like low modulus and a breathable property.

\subsection{Mechanical Characterization of the Substrate and Adhesive}

To synthesize the substrate material, we used polydimethylsiloxane (Sylgard 184, Dow Inc., Pittsburg, CA, USA) and Ecoflex (Smooth-on Inc.). Furthermore, the silbione (Elkem Silicones) and polydimethylsiloxane (PDMS) were also used as adhesives. Each was prepared following their technical data specifications. A PDMS was mixed by selected ratios (1:20,1:30, and 1:40) of a precursor and a curing agent and cured at hot plate. The Ecoflex was mixed with a 1:1 ratio of part A and part B, and then cured at ambient temperature. The silbione was also mixed with a 1:1 ratio of their two precursors and cured on a hot plate. Both the mechanical properties of the substrate, as well as the adhesion energy of the adhesives, were measured using a $90^{\circ}$ peeling test from the Instron 900 series tensile test machine [51]. All of the test samples were cut $20 \mathrm{~mm} \times 70 \mathrm{~mm}$ in size. Double-sided tape was then attached between the T-shape stage and a slide glass. The front side of the sample (approximately $10 \mathrm{~mm}$ ) was fixed onto the test jig using PET film and double-sided tape. Samples were then attached onto the slide glass (approximately $30 \mathrm{~mm}$ from the back) set at a $25 \mathrm{~mm}$ distance between the sample and the end of the test jig. Commercial 3M tape was then attached to the top of the sample to prevent sample delamination while measurements were undertaken. The samples were stretched at a rate of $20 \mathrm{~mm}$ per minute to generate a stress-strain curve. A graphic software was used to calculate the adhesion energy of each adhesive. Therefore, the area from 0 to strain value $(\mathrm{mm})$, when force/width $(\mathrm{N} / \mathrm{m})$ is the maximum in the stress-strain curve, is the tensile force (Newton, $\mathrm{N}$ ) applied to a sample that made contact with the glass slide. Finally, the adhesion energy $\left(\mathrm{J} / \mathrm{m}^{2}\right)$ was able to be calculated when the tensile force $(\mathrm{N})$ was divided by a thickness of the sample.

\subsection{Water Vapor Transmission Rate (WVTR) Test}

Each sample was tested for its breathability using a well-documented industrial water vapor transmission rate test (ASTM F1249). In this method, dry gas is swept through a chamber where test films act as membranes through the separation of wet and dry gas streams. The partial pressure difference is a driving force for the water vapor to permeate through the film from the high pressure side to the low-pressure side. The barrier of the film then regulates the amount of water vapor transfer; this procedure was performed continuously while being measured by a detector at the outgoing stream of the dry side.

We, therefore, mimicked this portion of the test to establish the WVTR. In a vacuum chamber, a beaker was filled with hot water for the "wet side" and then covered with both porous and nonporous substrates. The outside of the beaker then acted as the "dry side." Next, a digital thermo-hygrometer was placed inside the chamber to monitor the humidity in the vacuum for $1 \mathrm{~h}$. The humidity change was measured in real-time every $10 \mathrm{~min}$.

\subsection{Light Emission and Near-IR Recognition Test}

The light emission from the micro-IR LEDs in the fiducial marker was evaluated using a power supply (E3648A Dual Output Power Supply, Agilent Technologies, Inc., Santa Clara, CA, USA). Near-IR recognition was also evaluated by thermal imaging cameras (E75SC, FLIR Systems, Inc., Wilsonville, OR, USA) and near-IR cameras (custom-made, Korea Institute of Science and Technology, Seoul, South Korea). 


\subsection{Demonstration of Skin Adhesion to the Patch}

The fiducial marker patch was tested for its skin adhesion properties on a silicone-based phantom model (custom-made, Korea Institute of Science and Technology) and a human back. The patch was firstly attached to the phantom model (connected to the power supply) so that the light of the micro-IR LED light was activated. Patch adhesion was then evaluated by stretching with two hands. Moreover, to evaluate the real skin adhesion, the fiducial marker patch was attached to a human's back skin. The following 4 movements were repeatedly carried out to evaluate both the adhesion properties of the patch and the light emission characteristics of the micro-IR LED: standing straight, bending the waist forward, pulling two arms to the back, and waist twisting.

\section{Results and Discussion}

\subsection{Mechanical Characterization and Optimization of Patch Substrate and Adhesive}

In order to fabricate a stretchable and adhesive fiducial marker patch, a substrate was selected by comparing the mechanical performance of candidate substrates. First, PDMS 1:20 and Ecoflex were prepared, respectively. The as-prepared sample was then placed onto a glass plate attached to a T-shape stage (Figure 3a). Next, one end of the sample was then fixed to the test jig where the PET film was attached and then measured on a commercial tensile machine at a $90^{\circ}$ (Figure 3b,c). The mechanical properties were obtained while the sample was in pull-up mode. Among the substrates, the PDMS 1:20 sample stretched well early on $(\sim 50 \%)$, but broke shortly after. This was different for the Ecoflex, which had the ability to stretch up to a strain of $300 \%$ without breaking (Figure $3 \mathrm{~d}$ ). Next, the PDMS 1:20, PDMS 1:30, PDMS 1:40, and the silbione were then prepared as the adhesives. We also observed their mechanical properties in a similar way (Figure 3e), with the adhesion energies of each material calculated based on the results. Among them, the silbione sample was found with the most superior adhesion energy compared to the other adhesives (Figure 3f). Based on these results, the Ecoflex and silbione were finally selected for the fiducial marker patch.

a
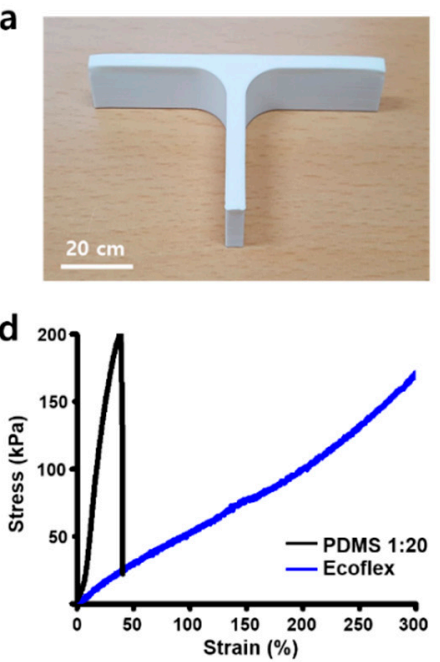
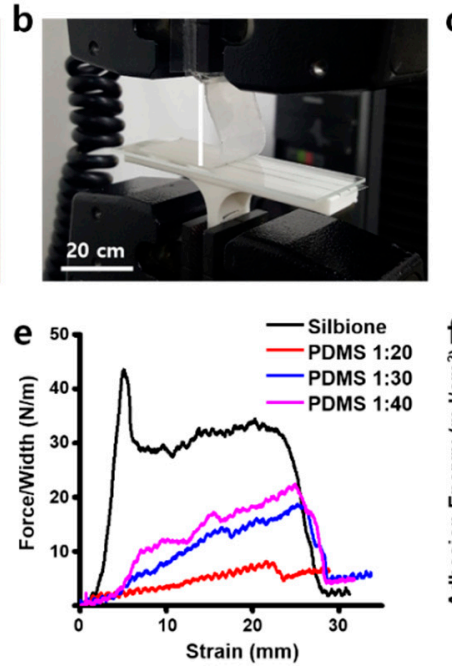
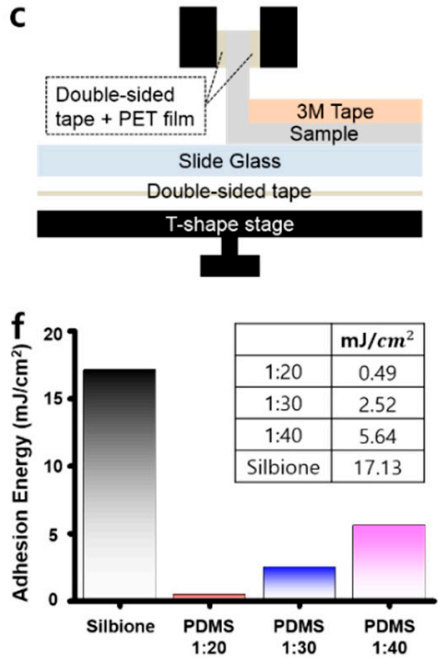

Figure 3. Mechanical characterizations of the patch components. (a) 3D-printed T-shape stage for the adhesion test. (b) The adhesion test using T-shape stage and tensile machine. (c) The components of the adhesion test system. (d) The stress-strain curve of substrate materials. (e) The stress-strain curve of adhesives. (f) The adhesion energy calculation results of adhesives. Inset: the adhesion energy of them.

We tested the electromechanical coupling of the interconnect material. When the interconnects were stretched to 30\%, the LED remained lit (Figure 2b). They also showed stable resistance through cyclic testing (Figure 2c). The resistance was slightly increased, but it was almost stable during the test 
(approximately under $5 \mathrm{ohm}$ ). Therefore, we determined the proper stretchable substrate, interconnect, and adhesive for the best fiducial marker.

\subsection{Improvement on Skin-Like Properties after the Pore Patterns Adoption}

It was important to achieve skin-like mechanical properties. This is to prevent the patch popping out and causing delamination due to the difference in mechanical properties between the skin and the patch if the patient was to move. The patch may also cause patient discomfort or inflammation when attached for long periods of time if the patch is not breathable. To prevent these problems and give the patch a skin-like property, pore patterning was adopted and we compared the properties before and after.

When we compared the strain-stress curves of nonporous (NP) and porous (P) substrates, the porous substrate showed lower modulus under $100 \mathrm{kPa}$ at $150 \%$ strain in comparison to the nonporous substrate, which is closer to the physical properties of human skin (Figure 4a). The adhesion energy, however, was found to only slightly decrease for the porous substrate due to the reduction in surface area by pore patterns (Figure $4 \mathrm{~b}$ ). The water vapor transmission rate (WVTR) was then tested using hot water and implemented simply to investigate the breathability of the two substrates. Figure $4 \mathrm{c}$ shows the results of the relative humidity on the dry side of the chamber, which was found to sharply increase on the porous substrate for $30 \mathrm{~min}$.
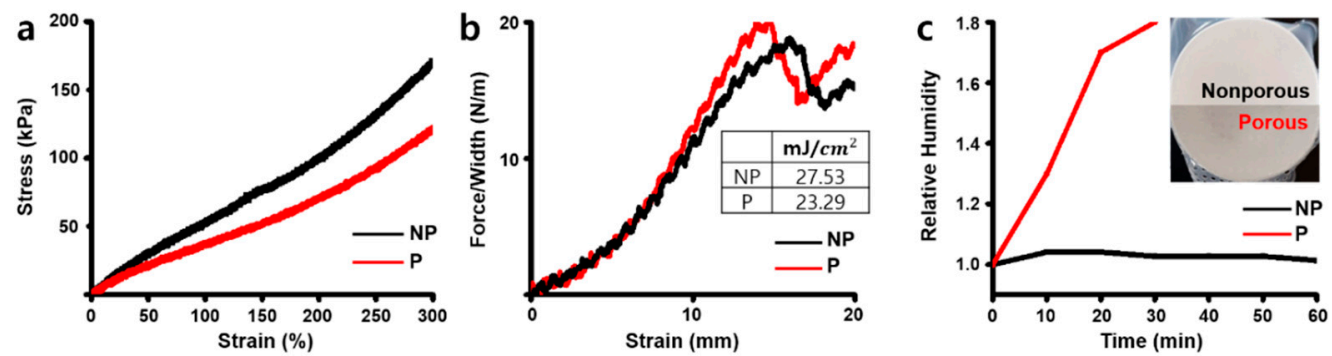

d

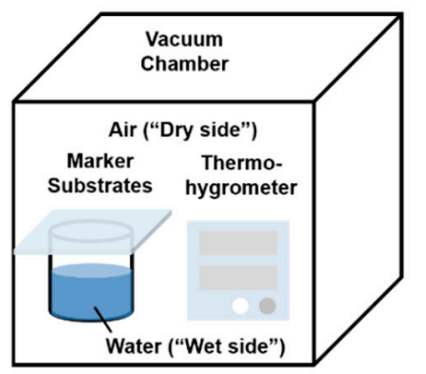

e

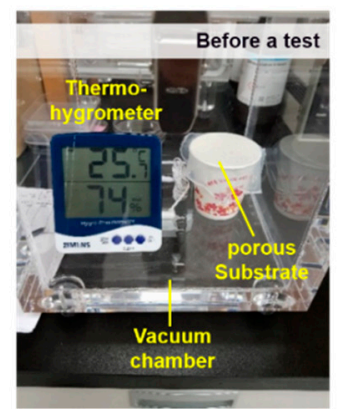

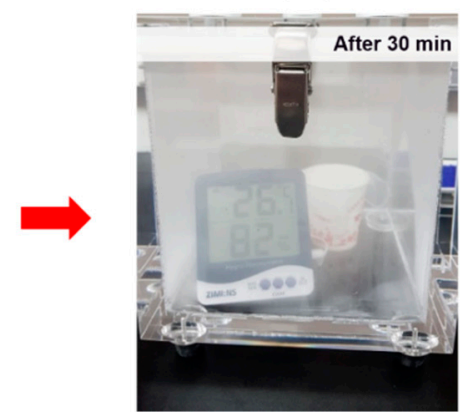

Figure 4. Mechanical characterizations of the skin-like porous patch. (a) The stress-strain curve of both nonporous (black) and porous substrate (red). (b) The stress-strain curve of adhesives on both nonporous (black) and porous substrate (red). Inset: the adhesion energy of them. (c) The relative humidity of both nonporous (black) and porous substrate (red). Inset: the image of nonporous (top) and porous substrate (bottom). (d) The structure of water vapor transmission rate test chamber inspired by ASTM F1249. (e) Before and after the water vapor transmission rate test of the porous substrate.

In contrast, the nonporous substrate was not able to transmit steam from the "wet side" of the beaker to the "dry side." Figure $4 \mathrm{~d}$,e shows that the porous substrate did in fact transmit the steam at a much faster rate. Through this, we concluded that the pore patterns not only give the patch a skin-like modulus but also breathability expressed by vapor transmission, so it makes the patch more comfortable for the patient's skin. 


\subsection{Light Emission and Near-IR Recognition Test}

Generally, fiducial markers should be responsive to the two light sources of the optical tracking device and the C-shaped arm (C-arm) in the surgical navigation systems to display the affected area. Typical optical tracking devices often use $850 \mathrm{~nm}$ near-IR cameras that recognize reflection patterns through a difference in the near-IR absorbance, and thus noninvasively displaying the position of the affected part in real-time. The C-arm, which is commonly used as a CT imaging device, visualizes the affected part via X-rays. In order to use the patch as a fiducial marker, it must be recognized on these devices. Specifically, the fiducial marker generally uses an optical tracking device, which serves to define the patient's coordinates with the marker in surgical navigation systems, so it must operate at near-IR light. For the use as a fiducial marker, we tested the light emission and wavelength compatibility (i.e., $850 \mathrm{~nm}$ ) of the six micro-IR LEDs attached to a patch. We first tested whether or not the LEDs connected to the stretchable interconnects emitted light. The LEDs for all the patches $(n>10)$ were found to emit light within a threshold voltage of 7-8 V. We also verified the light response of the patches, which maintained a voltage of $11 \mathrm{~V}$ (Figure 5a). To evaluate the compatibility and selective resolution for near-IR rays, images were obtained at each voltage using a thermal imaging camera and a near-IR camera at all wavelengths (Figure $5 b, c)$. The patch was found to show no light emission below $7 \mathrm{~V}$. On the contrary, at $9 \mathrm{~V}$ and above, the brightness was too high, so the individual spots could not be distinguished. From these results, we confirmed that the optimal near-IR resolution voltage of the patch was around $8 \mathrm{~V}$, which was typically where the LED size and the light source size were in a 1:1 ratio. Furthermore, the marker was also shown to be selectively observed when it was analyzed with the near-IR camera as compared to the thermal imaging camera. Micro-CT imaging was also used to verify the X-ray stability of the LEDs (Figure S1). We confirm that the LEDs used in the patch could operate without any damage when exposed to the X-ray. This then proves that the patch has good responsiveness and stability at near-IR and X-ray wavelengths and can be sufficiently used as a fiducial marker for patients under surgical navigation systems.

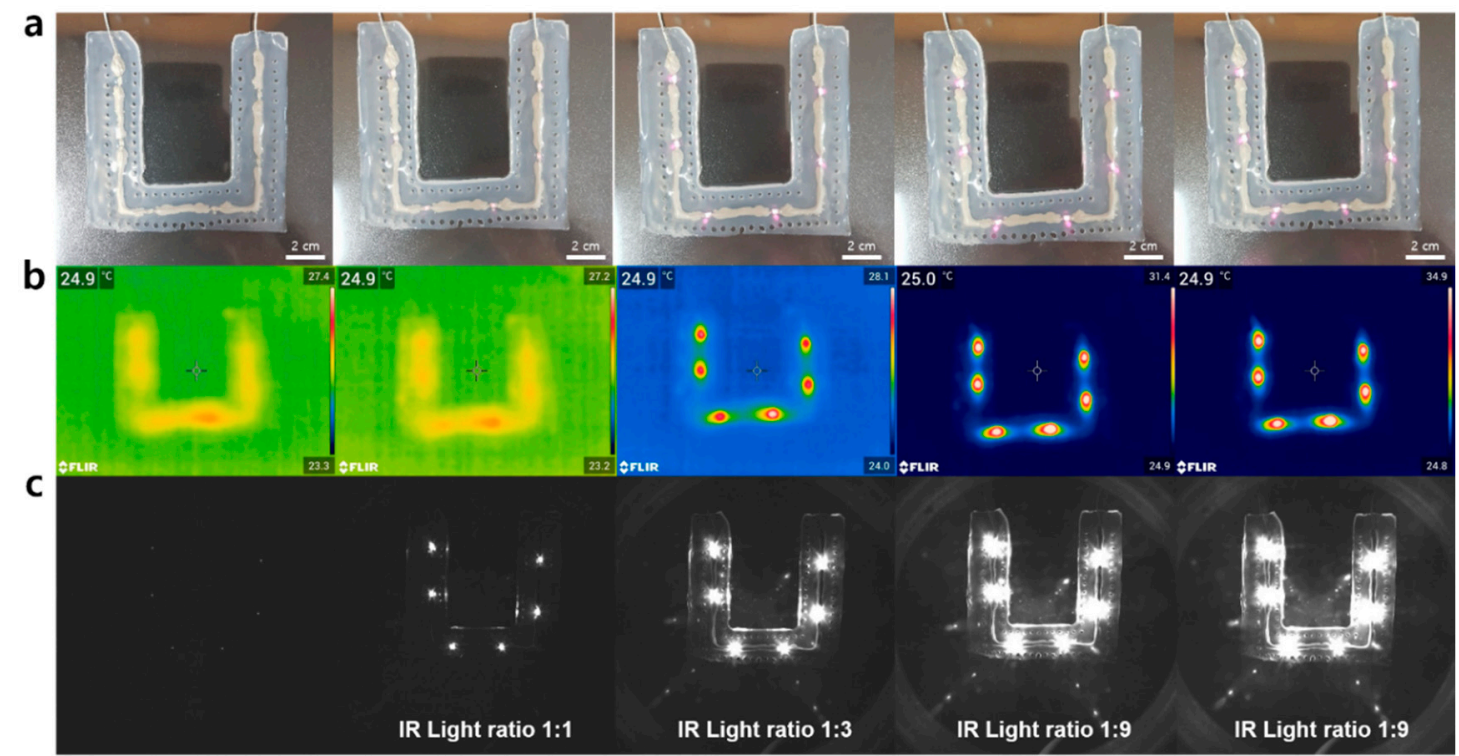

Figure 5. Light emission and near IR recognition test of the patch. (a) Images of the fiducial marker patch. (b) Thermal imaging camera images of the patch. (c) Near-IR camera images of the patch.

\subsection{Skin-Conformal Adhesion of the Patch}

Currently, surgical navigation systems are mainly used for spinal surgery. The patch was also developed with spinal surgery in mind, so the direct attachment to the back of a human subject was evaluated to test its adhesion to real skin. During this evaluation, the person used for the study was 
asked to stand straight (Figure 6a), bend his waist forward (Figure 6b), pull two arms back (Figure 6c), and to twist his waist (Figure $6 \mathrm{~d}$ ) repeatedly. As a result, the subject felt no discomfort caused by the rigidity of the LEDs when the patch was attached to the back. It was proved that the power was stably supplied by the stretchable interconnects in the patch because the LEDs on the patch were not turned off while four different movements were implemented. This result indicates that the patch could be a useful fiducial marker for patients due to its advantageous skin-conformal adhesion properties, even when the patient moves.

a

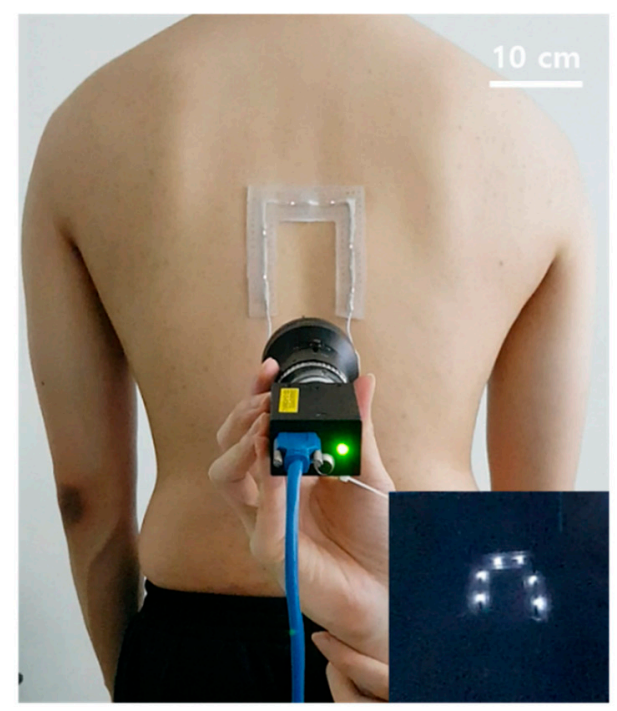

C

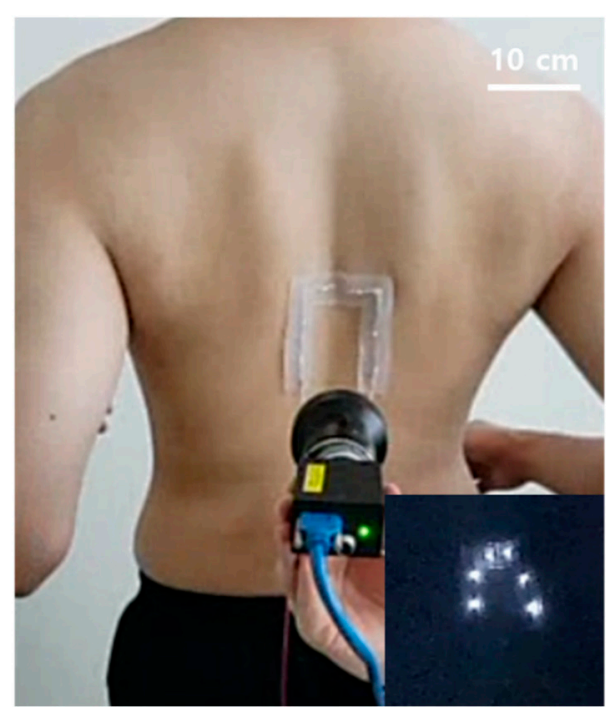

b

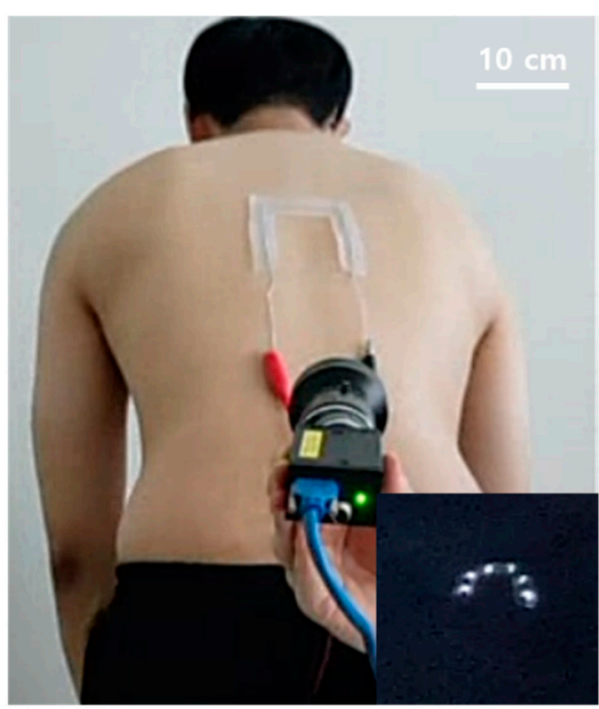

d

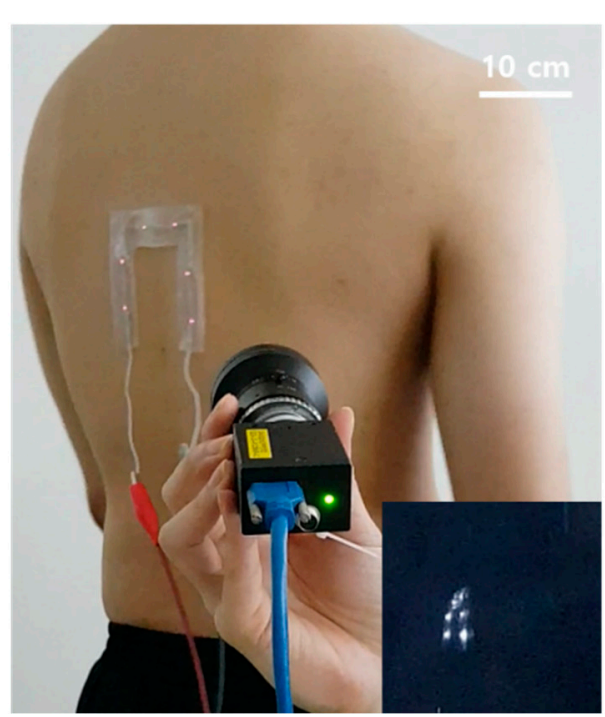

Figure 6. Skin-conformal adhesion demonstrations of the patch. (a) Standing straight. (b) Bending the waist forward. (c) Pulling two arms to the back. (d) Twisting the waist.

\section{Conclusions}

In this study, we optimized the proper materials to create a fiducial marker patch with a low modulus and excellent adhesion energy. We adopted pore patterning to ensure the patch had a skin-like mechanical property and breathability. The IR-LEDs built into the patch clearly displayed the attached area within the thermal imaging camera, near-IR camera, and micro-CT. When the patch was attached to a human back, we found that the skin-conformal adhesion and continuous light emission stability of the patch persisted while various movements were undertaken by the subject. The as-synthesized patch was also not rigid because of its rubbery substrate and soft adhesive, so it 
showed good skin-conformal adhesion to a human's back skin. Therefore, we expect that the patch will be a new candidate as a skin-conforming, stretchable, and breathable fiducial marker patch for surgical navigation systems.

Supplementary Materials: The following are available online at http://www.mdpi.com/2072-666X/11/2/194/s1, Figure S1: X-ray stability and recognition of the micro-IR LED with a micro-CT machine.

Author Contributions: Conceptualization, D.L. and D.S.(Donghee Son); Methodology, S.L. (Sangkyu Lee), D.S. (Duhwan Seong), J.Y., S.L. (Sungjun Lee) and D.S. (Donghee Son); Software, D.L.; Validation, S.L. (Sangkyu Lee), D.S. (Duhwan Seong), and D.S. (Donghee Son); Formal Analysis, S.L. (Sangkyu Lee), D.S. (Duhwan Seong), and D.S. (Donghee Son); Investigation, S.L. (Sangkyu Lee), D.S. (Duhwan Seong), and D.S. (Donghee Son); Resources, D.L., H.W.B., and D.S. (Donghee Son); Data Curation, S.L. (Sangkyu Lee), D.S. (Duhwan Seong), and D.S. (Donghee Son); Writing-Original Draft Preparation, S.L. (Sangkyu Lee), D.S. (Duhwan Seong), J.Y., and D.S. (Donghee Son); Writing-Review \& Editing, S.L. (Sangkyu Lee), D.S. (Duhwan Seong), and D.S. (Donghee Son); Visualization, S.L. (Sangkyu Lee), D.S. (Duhwan Seong), J.Y., S.L. (Sungjun Lee); Supervision, D.L., H.W.B., and D.S. (Donghee Son); Project Administration, D.L. and D.S. (Donghee Son); Funding Acquisition, D.L. Sangkyu Lee, Duhwan Seong equally contributed to this work. All authors have read and agreed to the published version of the manuscript.

Funding: This material is based on research supported by the Ministry of Trade Industry \& Energy (Korea), the Ministry of Science \& ICT (MSIT, Korea), and the Ministry of Health \& Welfare (Korea) under a Technology Development Program for AI-Bio-Robot-Medicine Convergence (20001655).

Conflicts of Interest: The authors declare no conflict of interest.

\section{References}

1. Choi, H.; Cho, B.; Masamune, K.; Hashizume, M.; Hong, J. An effective visualization technique for depth perception in AR-based surgical navigation. Int. J. Med. Robot. Comput. Assist. Surg. 2016, 12, 62-72. [CrossRef] [PubMed]

2. Li, L.; Yang, J.; Chu, Y.; Wu, W.; Xue, J.; Liang, P.; Chen, L. A Novel AR Navigation System for Endoscopic Sinus and Skull Base Surgery: A Feasibility Study. PLoS ONE 2016, 11, 1-17.

3. Suenaga, H.; Hoang, T.H.; Liao, H.; Masamune, K.; Dohi, T.; Hoshi, K.; Mori, Y.; Takato, T. Real-time in situ three-dimensional integral videography and surgical navigation using AR: A pilot study. Int. J. Oral Sci. 2013, 5, 98-102. [CrossRef]

4. Hong, J.S. Medical AR and Virtual Reality. J. Korean Soc. Radiol. 2019, 80, 226-238. [CrossRef]

5. Choi, H.; Hong, J. Development of a Surgical navigation system using AR. J. Biomed. Inform. 2015, 55, 124-131.

6. Sielhorst, T.; Feuerstein, M.; Navab, N. Advanced Medical Displays: A Literature Review of AR. J. Disp. Technol. 2008, 4, 451-467. [CrossRef]

7. Vávra, P.; Roman, J.; Zonča, P.; Ihnát, P.; Němec, M.; Kumar, J.; Habib, N.; El-Gendi, A. Recent Development of Augmented Reality in Surgery: A Review. J. Healthc. Eng. 2017, 1-9. [CrossRef]

8. Gurney-Champion, O.J.; Lens, E.; van der Horst, A.; Houweling, A.C.; Klaassen, R.; van Hooft, J.E.; Stoke, J.; van Tienhoven, G.; Nederveen, A.J.; Bel, A. Visibility and artifacts of gold fiducial markers used for image guided radiation therapy of pancreatic cancer on MRI. Med. Phys. 2015, 42, 2638-2647. [CrossRef]

9. Hosseinian, S.; Arefi, H.; Navab, N. Toward an End-to-End Calibration for Mobile C-Arm in Combination with a Depth Sensor for Surgical AR Applications. Sensors 2020, 20, 36-52. [CrossRef]

10. Ose, T.; Autio, J.A.; Ohno, M.; Nishigori, K.; Tanki, N.; Igesaka, A.; Mori, T.; Doi, H.; Wada, Y.; Nakajima, I.; et al. A novel Tungsten-based fiducial marker for multi-modal brain imaging. J. Neurosci. Methods 2019, 323, $22-31$. [CrossRef]

11. Maeda, M.; Ogawa, T.; Kiyokawa, K.; Takemura, H. Tracking of user position and orientation by stereo measurement of IR markers and orientation sensing. In Proceedings of the 8th International Symposium on Wearable Computers (ISWC'04), Arlington, TX, USA, 31 October-3 November 2004.

12. Nakazato, Y.; Kanbara, M.; Yokoya, N. Wearable AR system using invisible visual markers and an IR camera. In Proceedings of the 2005 9th IEEE International Symposium on Wearable Computers (ISWC'05), Osaka, Japan, 18-21 October 2005.

13. Lee, H.M.; Ryu, N.H.; Kim, E.K. IR LED marker detection method for production of multiple marker based on AR. J. Korea Inst. Electron. Commun. Sci. 2011, 6, 457-463. 
14. Kim, D.H.; Lu, N.; Ma, R.; Kim, Y.S.; Kim, R.H.; Wang, S.; Wu, J.; Won, S.M.; Tao, H.; Islam, A.; et al. Epidermal electronics. Science 2011, 333, 838-843. [CrossRef] [PubMed]

15. Kim, D.H.; Rogers, J.A. Stretchable Electronics: Materials, Strategies and Devices. Adv. Mater. 2008, 20, 4887-4892. [CrossRef]

16. Choi, S.J.; Lee, H.J.; Ghaffari, R.; Hyeon, T.; Kim, D.H. Recent Advances in Flexible and Stretchable Bio-Electronic Devices Integrated with Nanomaterials. Adv. Mater. 2016, 28, 4203-4218. [CrossRef] [PubMed]

17. Koo, J.H.; Kim, D.C.; Shim, H.J.; Kim, T.H.; Kim, D.H. Flexible and Stretchable Smart Display: Materials, Fabrication, Device Design, and System Integration. Adv. Funct. Mater. 2018, 28, 1801834. [CrossRef]

18. Son, D.; Lee, J.; Qiao, S.; Ghaffari, R.; Kim, J.; Lee, J.E.; Song, C.; Kim, S.J.; Lee, D.J.; Jun, S.W.; et al. Multifunctional wearable devices for diagnosis and therapy of movement disorders. Nat. Nanotechnol. 2014, 9, 397-404. [CrossRef] [PubMed]

19. Son, D.; Chae, S.I.; Kim, M.; Choi, M.K.; Yang, J.; Park, K.; Kale, V.S.; Koo, J.H.; Choi, C.; Lee, M.; et al. Colloidal Synthesis of Uniform-Sized Molybdenum Disulfide Nanosheets for Wafer-Scale Flexible Nonvolatile Memory. Adv. Mater. 2016, 28, 9326. [CrossRef]

20. Kim, J.; Son, D.; Lee, M.; Song, C.; Song, J.K.; Koo, J.H.; Lee, D.J.; Shim, J.H.; Kim, J.H.; Lee, M.; et al. A wearable multiplexed silicon nonvolatile memory array using nanocrystal charge confinement. Sci. Adv. 2016, 2, e1501101. [CrossRef]

21. Son, D.; Bao, Z. Nanomaterials in Skin-Inspired Electronics; Toward Soft and Robust Skin-like Electronic Nanosystems. ACS Nano 2018, 12, 11731. [CrossRef]

22. Choi, M.K.; Yang, J.; Kim, D.C.; Dai, Z.; Kim, J.; Seung, H.; Kale, V.S.; Sung, S.J.; Park, C.R.; Lu, N.; et al. Extremely Vivid, Highly Transparent, and Ultrathin Quantum Dot Light-Emitting Diodes. Adv. Mater. 2017, 30, 1703279. [CrossRef]

23. Kim, D.H.; Lu, N.; Ghaffari, R.; Kim, Y.S.; Lee, S.P.; Xu, L.; Wu, J.; Kim, R.H.; Song, J.; Liu, Z.; et al. Materials for Multifunctional Balloon Catheters with Capabilities in Cardiac Electrophysiological Mapping and Ablation Therapy. Nat. Mater. 2011, 10, 316-323. [CrossRef] [PubMed]

24. Kim, R.H.; Kim, D.H.; Xiao, J.; Kim, B.H.; Park, S.I.; Panilaitis, B.; Ghaffari, R.; Yao, J.; Li, M.; Liu, Z.; et al. Waterproof AlInGaP Optoelectronics on Flexible Tubing, Sutures, Gloves and Other Unusual Substrates with Application Examples in Biomedicine and Robotics. Nat. Mater. 2010, 9, 929-937. [CrossRef] [PubMed]

25. Yokota, T.; Zalar, P.; Kaltenbrunner, M.; Jinno, H.; Matsuhisa, N.; Kitanosako, H.; Tachibana, Y.; Yukita, W.; Koizumi, M.; Someya, T. Ultraflexible organic photonic skin. Sci. Adv. 2016, 2, e1501856. [CrossRef] [PubMed]

26. Kaltenbrunner, M.; Sekitani, T.; Reeder, J.; Yokota, T.; Kuribara, K.; Tokuhara, T.; Drack, M.; Schwödiauer, R.; Graz, I.; Bauer-Gogonea, S.; et al. An ultra-lightweight design for imperceptible plastic electronics. Nature 2013, 499, 458-463. [CrossRef] [PubMed]

27. Wang, S.; Xu, J.; Wang, W.; Wang, G.N.; Rastak, R.; Molina-Lopez, F.; Chung, J.W.; Niu, S.; Feig, V.R.; Lopez, J.; et al. Skin electronics from scalable fabrication of an intrinsically stretchable transistor array. Nature 2018, 555, 83-88. [CrossRef] [PubMed]

28. Xu, J.; Wang, S.; Wang, G.J.N.; Zhu, C.; Luo, S.; Jin, L.; Gu, X.; Chen, S.; Feig, V.R.; To, J.W.F.; et al. Highly stretchable polymer semiconductor films through the nanoconfinement effect. Science 2017, 355, 59-64. [CrossRef]

29. Lipomi, D.J.; Vosgueritchian, M.; Tee, B.C.K.; Hellstrom, S.L.; Lee, J.A.; Fox, C.H.; Bao, Z. Skin-like pressure and strain sensors based on transparent, elastic films of carbon nanotubes. Nat. Nanotechnol. 2011, 6, 788. [CrossRef]

30. Huang, Z.; Hao, Y.; Li, Y.; Hu, H.; Wang, C.; Nomoto, A.; Pan, T.; Gu, Y.; Chen, Y.; Zhang, T.; et al. Three-dimensional integrated stretchable electronics. Nat. Electron. 2018, 1, 473-480. [CrossRef]

31. Sim, K.; Rao, Z.; Kim, H.J.; Thukral, A.; Shim, H.; Yu, C. Fully rubbery integrated electronics from high effective mobility intrinsically stretchable semiconductors. Sci. Adv. 2019, 5, eaav5749. [CrossRef]

32. Shim, H.; Sim, K.; Ershad, F.; Yang, P.; Thukral, A.; Rao, Z.; Kim, H.J.; Liu, Y.; Wang, X.; Gu, G.; et al. Stretchable elastic synaptic transistors for neurologically integrated soft engineering systems. Sci. Adv. 2019, 5, eaax4961. [CrossRef]

33. Rogers, J.A.; Someya, T.; Huang, Y. Materials and Mechanics for Stretchable Electronics. Science 2010, 327, 1603-1607. [CrossRef] 
34. Sekitani, T.; Nakajima, H.; Maeda, H.; Fukushima, T.; Aida, T.; Hata, K.; Someya, T. Stretchable active-matrix organic light-emitting diode display using printable elastic conductors. Nat. Mater. 2009, 8, 494-499. [CrossRef] [PubMed]

35. Fan, J.A.; Yeo, W.H.; Su, Y.; Hattori, Y.; Lee, W.; Jung, S.Y.; Zhang, Y.; Liu, Z.; Cheng, H.; Falgout, L.; et al. Fractal design concepts for stretchable electronics. Nat. Commun. 2014, 5, 3266. [CrossRef] [PubMed]

36. Choi, S.J.; Park, J.K.; Hyun, W.; Kim, J.; Kim, J.; Lee, Y.B.; Song, C.; Hwang, H.J.; Kim, J.H.; Hyeon, T.; et al. Stretchable Heater Using Ligand-Exchanged Silver Nanowire Nanocomposite for Wearable Articular Thermotherapy. ACS Nano 2015, 9, 6626-6633. [CrossRef] [PubMed]

37. Kang, J.; Son, D.; Wang, G.N.; Liu, Y.; Lopez, J.; Kim, Y.; Oh, J.Y.; Katsumata, T.; Mun, J.; Lee, Y.; et al. Tough and water-insensitive self-healing elastomer for robust electronic skin. Adv. Mater. 2018, 30, 1706846. [CrossRef]

38. Son, D.; Kang, J.; Vardoulis, O.; Kim, Y.; Matsuhisa, N.; Oh, J.Y.; To, J.W.; Mun, J.; Katsumata, T.; Liu, Y.; et al. An integrated self-healable electronic skin system fabricated via dynamic reconstruction of a nanostructured conducting network. Nat. Nanotechnol. 2018, 13, 1057-1065. [CrossRef]

39. Kang, J.; Son, D.; Vardoulis, O.; Mun, J.W.; Matsuhisa, N.; Kim, Y.; Kim, J.; Tok, J.B.H.; Bao, Z. Modular and Reconfigurable Stretchable Electronic Systems. Adv. Mater. Technol. 2018, 4, 1800417. [CrossRef]

40. Kim, S.H.; Seo, H.S.; Kang, J.H.; Hong, J.Y.; Seong, D.H.; Kim, H.J.; Kim, J.; Mun, J.; Youn, I.; Kim, J.; et al. An Ultrastretchable and Self-Healable Nanocomposite Conductor Enabled by Autonomously Percolative Electrical Pathways. ACS Nano 2019, 13, 6531-6539. [CrossRef]

41. Oh, J.Y.; Son, D.; Katsumata, T.; Lee, Y.; Kim, Y.; Lopez, J.; Wu, H.C.; Kang, J.; Park, J.; Gu, X.; et al. Stretchable self-healable semiconducting polymer film for active-matrix strain-sensing array. Sci. Adv. 2019, 5, eaav3097. [CrossRef]

42. Cao, Y.; Wu, H.; Allec, S.I.; Wong, B.M.; Nguyen, D.S.; Wang, C. A Highly Stretchy, Transparent Elastomer with the Capability to Automatically Self-Heal Underwater. Adv. Mater. 2018, 30, 1804602. [CrossRef]

43. Zhang, Q.; Niu, S.; Wang, L.; Lopez, J.; Chen, S.; Cai, Y.; Du, R.; Liu, Y.; Lai, J.C.; Liu, L.; et al. An Elastic Autonomous Self-Healing Capacitive Sensor Based on a Dynamic Dual Crosslinked Chemical System. Adv. Mater. 2018, 30, 1801435. [CrossRef] [PubMed]

44. Yan, X.; Liu, Z.; Zhang, Q.; Lopez, J.; Wang, H.; Wu, H.C.; Niu, S.; Yan, H.; Wang, S.; Lei, T.; et al. Quadruple H-Bonding Cross-Linked Supramolecular Polymeric Materials as Substrates for Stretchable, Antitearing, and Self-Healable Thin Film Electrodes. J. Am. Chem. Soc. 2018, 140, 5280-5289. [CrossRef] [PubMed]

45. Li, C.H.; Wang, C.; Keplinger, C.; Zui, J.L.; Jin, L.; Sun, Y.; Zheng, P.; Cao, Y.; Lissel, F.; Linder, C.; et al. A highly stretchable autonomous self-healing elastomer. Nat. Chem. 2016, 8, 618-624. [CrossRef] [PubMed]

46. Rao, Y.L.; Chortos, A.; Pfattner, R.; Lissel, F.; Chiu, Y.C.; Feig, V.; Xu, J.; Kurosawa, T.; Gu, X.; Wang, C.; et al. Stretchable Self-Healing Polymeric Dielectrics Cross-Linked Through Metal-Ligand Coordination. J. Am. Chem. Soc. 2016, 138, 6020-6027. [CrossRef] [PubMed]

47. Oh, J.Y.; Rondeau-Gagné, S.; Chiu, Y.C.; Chortos, A.; Lissel, F.; Wnag, G.J.W.; Schroeder, B.C.; Kurosawa, T.; Lopez, J.; Katsumata, T.; et al. Intrinsically stretchable and healable semiconducting polymer for organic transistors. Nature 2016, 539, 411-421. [CrossRef] [PubMed]

48. Kang, J.; Tok, J.B.H.; Bao, Z. Self-healing soft electronics. Nat. Electron. 2019, 2, 144-150. [CrossRef]

49. Khatib, M.; Huynh, T.P.; Deng, Y.; Horev, Y.D.; Saliba, W.; Wu, W.; Haick, H. A Freestanding Stretchable and Multifunctional Transistor with Intrinsic Self-Healing Properties of all Device Components. Small 2019, 15, 1803939. [CrossRef]

50. Yang, Y.; Urban, M.W. Self-healing polymeric materials. Chem. Soc. Rev. 2013, 42, 7446-7467. [CrossRef]

51. Yuk, H.; Zhang, T.; Parada, G.A.; Liu, X.; Zhao, X. Skin-inspired hydrogel-elastomer hybrids with robust interfaces and functional microstructures. Nat. Commun. 2016, 7, 1-11. [CrossRef]

(C) 2020 by the authors. Licensee MDPI, Basel, Switzerland. This article is an open access article distributed under the terms and conditions of the Creative Commons Attribution (CC BY) license (http://creativecommons.org/licenses/by/4.0/). 